\title{
Decreasing the Peril of Antimicrobial Resistance Through Enhanced Health Literacy in Outpatient Settings: An Underrecognized Approach to Advance Antimicrobial Stewardship
}

\author{
Elizabeth D. Hermsen · Erina L. MacGeorge • May-Lynn Andresen • \\ Laurie M. Myers · Christian J. Lillis · Bernard M. Rosof
}

Received: June 28, 2019 / Published online: January 17, 2020

(C) The Author(s) 2020

\begin{abstract}
Globally, antimicrobial resistance (AMR) is a serious problem causing 700,000 deaths annually. By 2050, AMR is expected to cause approximately 10 million deaths globally each year if allowed to increase at the present rate. Many individuals have limited knowledge regarding appropriate antibiotic use and AMR.
\end{abstract}

Enhanced Digital Features To view enhanced digital features for this article go to https://doi.org/10.6084/ m9.figshare.11322125.

E. D. Hermsen $(\varangle) \cdot$ L. M. Myers

Merck \& Co., Inc., Kenilworth, NJ, USA

e-mail: elizabeth.hermsen@merck.com

E. L. MacGeorge

Penn State, University Park, PA, USA

M.-L. Andresen · B. M. Rosof

QHC Advisory Group, Lloyd Harbor, NY, USA

C. J. Lillis

Peggy Lillis Foundation, Radnor, PA, USA

B. M. Rosof

Donald and Barbara Zucker School of Medicine at

Hofstra/Northwell, Hempstead, NY, USA
Most antibiotic use occurs in the outpatient setting, with approximately 30\% of antibiotics prescribed deemed unnecessary. Antimicrobial stewardship (AMS) is a means to reduce inappropriate antibiotic use and AMR. While existing AMS efforts generally focus on the inpatient setting, a significant gap is present in the outpatient setting. A common theme across various national action plans to reduce AMR is the need for education and awareness. The importance of communicating information in a manner easily comprehended by the patient in addition to productive clinician-patient dialogue cannot be overestimated. Enhancing the public's and patients' AMS health literacy is an underrecognized approach to help address AMR. We describe Four Core Elements of Enhancing AMS Health Literacy in the Outpatient Setting, utilizing the Centers for Disease Control and Prevention's framework: (1) leadership commitment, (2) intervention/action, (3) tracking/ reporting, and (4) education/expertise. We call upon leaders in outpatient settings to embrace this approach to curb inappropriate antimicrobial use.

Keywords: Antibiotic resistance; Antibiotic stewardship; Antibiotic use; Health literacy; Outpatient; Overprescribing; Patient communication; Patient-provider communication 


\section{Key Summary Points}

Antimicrobial resistance is a serious global threat necessitating reduction of inappropriate use of antimicrobials, which is prevalent in the outpatient setting.

Globally, significant misconceptions are present in the general public's knowledge of antibiotics and their appropriate use.

Health literacy is an underutilized but valuable way to enhance provider-patient communication and improve antimicrobial stewardship (AMS) in the outpatient setting.

Four core elements to enhance AMS health literacy, based on the Centers for Disease Control and Prevention's framework, are provided: (1) leadership commitment, (2) intervention/action, (3) tracking/ reporting, and (4) education/expertise.

Several methods and tools to bolster AMS health literacy are described.

\section{PEGGY LILLIS' STORY}

One Tuesday morning, Peggy, a 56-year-old kindergarten teacher, went to her dentist for a root canal and received a prescription for an antibiotic for a tooth abscess [1]. Three days later, Peggy missed work and was bedridden through the weekend because of severe diarrhea. After a phone call to her primary care provider on Saturday, she received a prescription for an antidiarrheal and was advised to see a gastroenterologist. Peggy began taking the antidiarrheal and continued taking the antibiotic. The possibility of Clostridium difficile (now Clostridioides difficile) infection (CDI) was not discussed by the physician or pharmacist, and Peggy did not know this was a potential adverse event associated with the antibiotic.

One week after her root canal, Peggy was admitted to the hospital where she was diagnosed with CDI and septic shock. Intravenous fluids and antibiotic therapy for CDI were started. Peggy was sedated and intubated. The following morning, Peggy was taken to the operating room. She survived the surgery, but her condition deteriorated throughout the day. Peggy passed away at 7:20 pm, 8 days after her root canal and what she thought was an innocuous antibiotic prescription.

In 2017 at least 12,800 individuals died as a result of CDI in the USA [2]. Peggy's story is just one of many poignant illustrations of the potential harmful effects of antibiotic use and the importance of provider-patient communication in discussing treatment options, weighing the benefits and risks of those options, and making an informed decision.

\section{ANTIMICROBIAL RESISTANCE}

Antimicrobial resistance (AMR), the ability of microorganisms to adapt and grow in the presence of antimicrobials, is a serious threat to population health, leading to increased morbidity, mortality, and cost [3]. AMR is responsible for an estimated 700,000 deaths annually around the globe [3]. In the USA, antibiotic-resistant bacteria cause at least 35,000 deaths and over 2.8 million illnesses each year [2]. By the year 2050 it is expected that AMR will contribute to 10 million deaths per year globally [3]. Resistance to antibiotics is of particular concern due to increasing prevalence and widespread inappropriate antibiotic use. The majority of antibiotic use in people occurs in the outpatient setting, with approximately 30\% of all antibiotic prescriptions considered inappropriate or unnecessary $[4,5]$.

To help address AMR, the World Health Organization (WHO) issued a global action plan on AMR, recommending that each country develop and implement a national action plan (Table 1) [6]. Several countries, including the USA, have followed suit and developed countryspecific plans for addressing AMR. Two common themes across various action plans include the need for increased awareness and education and the importance of antimicrobial stewardship (AMS) [6-8]. 
Table 1 CDC core elements, WHO objectives, and the United States National Action Plan goals on AMR/AMS

CDC core elements for outpatient antimicrobial stewardship [7]

1 Leadership Demonstrate dedication to and accountability for optimizing antibiotic prescribing and patient commitment safety

2 Intervention and Implement at least one policy or practice to improve antibiotic prescribing, assess whether it is action

3 Tracking and reporting

4 Education and expertise working, and modify as needed

Monitor antibiotic prescribing practices and offer regular feedback to clinicians, or have clinicians assess their own antibiotic prescribing practices themselves

Provide educational resources to clinicians and patients on antibiotic prescribing and ensure access to needed expertise on optimizing antibiotic prescribing

WHO global action plan on antimicrobial resistance: five objectives [6]

1 To improve awareness and understanding of AMR through effective communication, education, and training

2 To strengthen the knowledge and evidence base through surveillance and research

3 To reduce the incidence of infection through effective sanitation, hygiene, and infection prevention measures

4 To optimize the use of antimicrobial medicines in human and animal health

5 To develop the economic case for sustainable investment that takes account of the needs of all countries and to increase investment in new medicines, diagnostic tools, vaccines, and other interventions

\section{United States National Action Plan goals [8]}

1 Slow the emergence of resistant bacteria and prevent the spread of resistant infections

2 Strengthen national one-health surveillance efforts to combat resistance

3 Advance development and use of rapid and innovative diagnostic tests for identification and characterization of resistant bacteria

4 Accelerate basic and applied research and development for new antibiotics, other therapeutics, and vaccines

5 Improve international collaboration and capacities for antibiotic resistance prevention, surveillance, control, and antibiotic research and development

$A M R$ antimicrobial resistance, $A M S$ antimicrobial stewardship, $C D C$ centers for disease control and prevention, $W H O$ world health organization

The development of country-specific policies in high-income countries like the USA must acknowledge the capacity for AMR to spread across borders. At present, many low- and middle-income countries place few regulations on antibiotic use, allowing residents to selfmedicate without a prescription $[9,10]$. Poor sanitation, low literacy overall, and limited access to healthcare also contribute to elevated rates of AMR in these countries $[9,11]$. These circumstances make it essential to improve AMS in high-income countries with strategies that can be shared in other contexts.

\section{ANTIMICROBIAL STEWARDSHIP}

AMS refers to coordinated interventions designed to ensure that the correct antimicrobial drug, dose, route, and duration are selected with the goal of curing/preventing infection while minimizing unintended consequences, 
such as toxicity and the development of AMR $[7,8]$. Several national organizations have provided guidance for AMS, such as the Centers for Disease Control and Prevention's (CDC) core elements for AMS in the outpatient setting (Table 1) [7]. Although patient education and awareness are echoed across these recommendations, effective communication strategies and principles are not emphasized.

AMR and AMS are complicated topics that remain poorly understood by the general public [12]. Correspondingly, many patients make misinformed decisions about antibiotics such as failing to complete their full courses of treatment and sharing unused prescriptions with family members [9]. In order to succeed at increasing awareness and understanding, information must be communicated in a manner that the patient can comprehend and act onin other words, following principles of health literacy [13].

Increased awareness and education are not only needed for patients. Providers overprescribe antibiotics for many reasons [14]. Factors influencing prescribing decisions include, but are not limited to, time constraints, diagnostic uncertainty, "decision fatigue," perception that the risk of not treating is greater than the risk of overprescribing, perceived or explicit patient/caregiver demands, and patient satisfaction concerns $[5,14]$. Both patient and provider behaviors need to be considered in order to improve AMS. These points reinforce the importance of the two-sided nature of health literacy.

\section{HEALTH LITERACY}

Health literacy is defined as "the degree to which individuals have the capacity to obtain, communicate, process, and understand basic health information to make appropriate health decisions" [15]. Public health scholars emphasize that health literacy involves the bidirectional exchange between patients and health professionals, as well as the capacity to navigate the demands and complexity of the healthcare system [16].
Three levels of health literacy exist according to Nutbeam [17]. Functional health literacy entails possessing the fundamental ability to read and write and to function productively in everyday life. Communicative health literacy requires higher-level skills to partake in daily activities, extract information, and understand various forms of communication, in addition to applying the information learned. Critical health literacy involves utilizing advanced skills to analyze information critically and to proactively apply learnings to decision-making in various situations.

Only $12 \%$ of adults in the USA have proficient health literacy. Further, $28 \%$ of white adults and $65 \%$ of Hispanic adults have only basic or below basic health literacy [18]. Low health literacy impacts a person's ability to manage their health, take medications appropriately, and engage in shared decision-making. Populations especially prone to low health literacy include older adults, racial and ethnic minorities, those with low income or less education, and those with compromised health status [18]. Notably, even highly educated individuals can have low health literacy [18], including those who work in and around healthcare contexts. Health literacy is dynamic, i.e., it can vary for a given individual across different situations and can be impacted by factors such as fear and stress related to illness.

Health literacy is increasingly being recognized as modifiable [16], as people can become more health literate and participate in behaviors that enable them to make better and more informed healthcare decisions. Most people receive antibiotics periodically throughout their lifetimes, so improving patient and family AMS health literacy could impact both current and future antibiotic use and be a powerful tool to help curb the serious and ever-growing problem of AMR. For the purposes of this paper, we define AMS health literacy as the degree to which patient-provider interaction enables comprehension and informed decision-making regarding antimicrobial use, within the context of the healthcare system in which the interaction occurs. 


\section{KNOWLEDGE OF ANTIBIOTICS AND INFLUENCE OF HEALTH LITERACY}

To date, the public's understanding of AMR has been assessed in a variety of countries and regions through surveys and systematic literature reviews (data represented predominantly by surveys) [19-21]. A mixed level of understanding of antibiotic use was found across countries. Although generally viewed as a problem, many participants did not clearly understand AMR or recognize it as a major public health issue. Although many Americans claim to understand what AMR is, nearly half fail to recognize antibiotic overuse as a major problem [12]. In addition, there is significant room for improvement as $55 \%$ of those surveyed believed that viral infections could be cured with antibiotics. Further, almost half indicated that they did not take antibiotics as prescribed and many did not finish their course of antibiotics.

In the UK, survey results showed that the general public does not accurately understand AMR. Many thought AMR was due to the human body building immunity to the antibiotic rather than the bacteria becoming resistant to the antibiotic [20]. This fundamental misconception undercuts the public's ability to understand that antibiotics are a shared and depletable resource and that resistance can be transmitted from one person to another. Other individuals were suspicious of the concept of AMR, reporting that they thought there might be a financial motive behind it, a drug company "conspiracy," or someone else's problem. Further, they believed that the problem would be solved by experts and advancements [20].

Studies also provide evidence of important associations between health literacy, knowledge about antibiotics, and antibiotic consumption. In an urban Latino immigrant population in the USA, more than half of parents with limited health literacy reported that Motrin ${ }^{\circledR}$ (ibuprofen) was an antibiotic [22]. In a study evaluating knowledge of antibiotics and health literacy in the Berlin area, those who had taken antibiotics within the previous year had a better understanding of antibiotics than individuals who had not taken them [23]. Of the former, $88.7 \%$ patients indicated receiving guidance from a physician or pharmacist on how to take the antibiotic, reinforcing the importance of the provider-patient interaction. It was also reported that better health literacy was found in those who had not taken antibiotics in the previous year, suggesting that health literacy may be a preventive factor to use antibiotics more judiciously. This finding suggests that direct efforts to enhance health literacy are likely to reduce antibiotic consumption.

An association between poverty and AMR suggested that antimicrobial-resistant infections may be due in part to low literacy and limited education in addition to low health literacy [10]. Limited or insufficient health literacy generally correlated with an inadequate understanding of antibiotic use for infection treatment and a decrease in infection protective behavior, such as immunizations, but the results were not consistent [24].

Global/National action plans have stressed the importance of education/awareness as the foundation to improved AMS [6-8]. However, educational campaigns surrounding AMS have been passive, potentially short-lived, and often do not yield the desired outcomes [20, 25]. More educational initiatives on AMS are needed in the community [26] with consideration of how to achieve enduring effects.

Some clinicians believe that although AMR is a serious problem, they do not have personal responsibility or accountability [27]. There is a significant opportunity to improve AMS by helping clinicians understand that they play a vital role in educating patients on AMS, utilizing principles of health literacy. To address this need, we propose Four Core Elements of Enhancing AMS Health Literacy in the Outpatient Setting, adapted from the framework provided by the CDC [7]. Please note that this article is based on previously conducted studies and does not contain any studies with human participants or animals performed by any of the authors. 


\section{FOUR CORE ELEMENTS OF ENHANCING AMS HEALTH LITERACY IN THE OUTPATIENT SETTING}

Attention to health literacy regarding patients' understanding of antibiotic use and prescribing in community settings may contribute to an environment that promotes AMS and decreases AMR. As suggested by the aforementioned surveys and literature reviews, many misunderstandings and misperceptions regarding AMR and AMS remain with standard care and communication tools used to date. The CDC's Four Core Elements is a framework for use in the outpatient setting to improve AMS. It divides improvement efforts into four domains: (1) leadership commitment, (2) intervention/ action, (3) tracking/reporting, and (4) education/expertise. This framework can readily be adapted to enhance AMS health literacy.

\section{Leadership Commitment to AMS Health Literacy}

Lasting change begins with commitment at the highest level of a healthcare organization. A commitment to system changes can set the tone and create an environment that results in demonstrable impact. We have adapted the 10 attributes of a health literate organization into a gap analysis checklist that clinics can use to assess and monitor their commitment to AMS health literacy (Table 2). Importantly, these attributes require that leadership make AMS health literacy integral to system operations.

Targeting change at the organizational level, Koh et al. [29] proposed a Health Literate Care Model as a means by which healthcare organizations can infuse health literacy into all aspects of planning and operations. This model weaves health literacy into the widely adopted Chronic Care Model and includes relevant tools from the Health Literacy Universal Precautions Toolkit in order to maximize potential for system change [30]. The first three tools of the Health Literacy Universal Precautions Toolkit provide guidance for creating a health-literate organizational culture: form a team, create a health literacy improvement plan, and raise awareness. These actions would undoubtedly benefit endeavors to enhance AMS health literacy and would demonstrate leadership commitment to AMS health literacy.

\section{Interventions/Actions to Enhance AMS Health Literacy}

\section{Implement the Health Literate Care Model}

The Health Literate Care Model calls for approaching all patients with the assumption that they are at risk of not understanding information and then confirming and ensuring the patient's understanding. Most patients do not have the requisite understanding of antibiotics for proper AMS, as suggested by the aforementioned survey results. Therefore, the approach suggested by the Health Literate Care Model is applicable to enhancing AMS health literacy during patient-provider engagement.

\section{Use the CDC Clear Communication Index to Develop Patient Communication Materials} When creating educational resources for use with patients, organizations must ensure that the materials are developed using principles of health literacy. The CDC advises following the principles of health literacy for antibiotic prescribing using the Clear Communication Index (CCI) [31]. The CCI can also be used to create written information that will be understandable for patients with low health literacy. Figure 1 illustrates how applying the principles of health literacy can make a brochure on C. difficile, which caused Peggy Lillis' infection, easier for the patient to comprehend.

\section{Strengthen Health Literate Verbal Communication Skills}

Tools are available to effectively use plain language in verbal discussions, important when explaining the complexities of antibiotics. Choosing Wisely is an initiative to promote conversations between clinicians and patients with the goal of avoiding unnecessary treatment [32]. These communication strategies can be used to discuss risks associated with 
Table 2 Gap analysis checklist for AMS health literacy commitment (adapted from [28])

\begin{tabular}{|c|c|c|c|}
\hline Attribute & $\begin{array}{c}\text { Current } \\
\text { Activities }\end{array}$ & $\begin{array}{l}\text { Potential } \\
\text { Barriers }\end{array}$ & $\begin{array}{l}\text { Action Plan/ } \\
\text { Target Date }\end{array}$ \\
\hline \multicolumn{4}{|l|}{$\begin{array}{l}\text { 1. Has leadership that makes AMS health } \\
\text { literacy integral to its mission, structure, and } \\
\text { operations. }\end{array}$} \\
\hline \multicolumn{4}{|l|}{$\begin{array}{l}\text { 2. Integrates AMS health literacy into planning, } \\
\text { quality improvement and evaluates antibiotic } \\
\text { risks/benefits and prescribing patterns. }\end{array}$} \\
\hline \multicolumn{4}{|l|}{$\begin{array}{l}\text { 3. Educates the workforce on AMR and how to } \\
\text { be AMS health literate; monitors progress. }\end{array}$} \\
\hline \multicolumn{4}{|l|}{$\begin{array}{l}\text { 4. Includes populations served in the design, } \\
\text { implementation, and evaluation of health } \\
\text { information and services pertaining to AMR and } \\
\text { AMS; forms AMS committees that educate and } \\
\text { monitor progress. }\end{array}$} \\
\hline \multicolumn{4}{|l|}{$\begin{array}{l}\text { 5. Meets the needs of populations with a range } \\
\text { of AMS health literacy skills while avoiding } \\
\text { stigmatization. }\end{array}$} \\
\hline \multicolumn{4}{|l|}{$\begin{array}{l}\text { 6.Uses health literacy strategies in } \\
\text { interpersonal communications regarding } \\
\text { AMR/AMS and confirms understanding at all } \\
\text { points of contact. }\end{array}$} \\
\hline \multicolumn{4}{|l|}{$\begin{array}{l}\text { 7. Provides easy access to health information } \\
\text { and services pertaining to AMR/AMS and } \\
\text { navigation assistance to access websites with } \\
\text { AMR/AMS info. }\end{array}$} \\
\hline \multicolumn{4}{|l|}{$\begin{array}{l}\text { 8. Designs and distributes print, audiovisual, } \\
\text { and social media content that explains } \\
\text { AMR/AMS in a manner that is easy to } \\
\text { understand and act on. }\end{array}$} \\
\hline \multicolumn{4}{|l|}{$\begin{array}{l}\text { 9. Addresses AMS health literacy in high-risk } \\
\text { situations including care transitions and } \\
\text { communications about medicines. }\end{array}$} \\
\hline $\begin{array}{l}\text { 10.Communicates clearly which antibiotics } \\
\text { health plans cover, when a generic is } \\
\text { acceptable, and costs individuals will have to } \\
\text { pay for services. }\end{array}$ & & & \\
\hline
\end{tabular}

$A M R$ antimicrobial resistance, $A M S$ antimicrobial stewardship

antibiotics, including but not limited to AMR, and to enhance patient/caregiver efficacy at monitoring and managing symptoms when antibiotics are not prescribed.

In line with the aforementioned is "teachback," a general health literacy technique that providers can employ to ensure information is understood [30, 33]. The goal of teach-back is to ensure that medical information is explained clearly and in plain language. Teach-back allows for confirmation that patients understand how to take their antibiotics, providing a mechanism to enhance AMS [30,33]. The steps of teachback are as follows: 

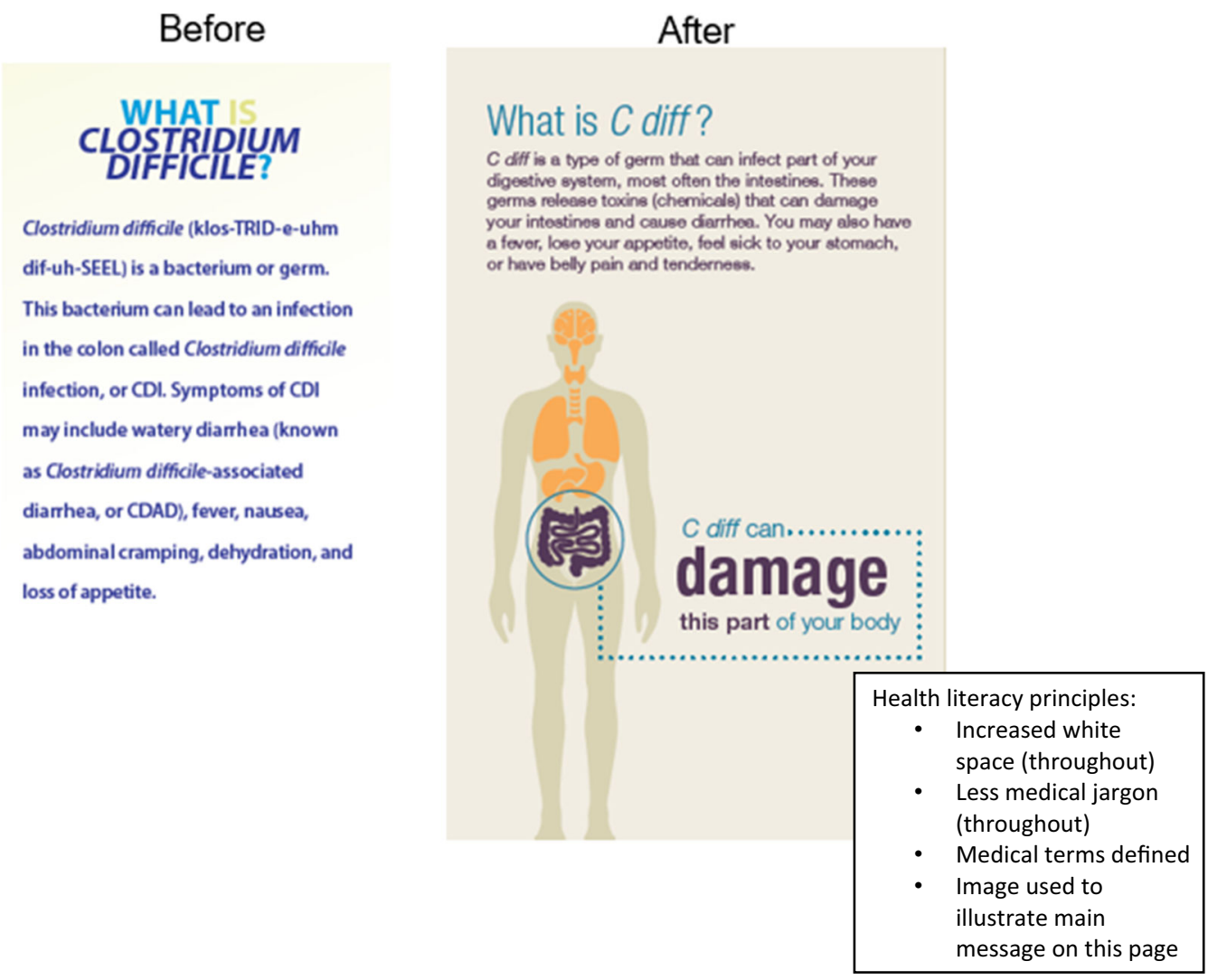

Fig. 1 Depiction of a segment of a $C$. difficile brochure before and after applying health literacy principles

1. Clinician explains either a new concept, health information, advice, or change in management.

2. Clinician assesses patient recall and comprehension.

3. Clinician clarifies and amends the explanation, if necessary.

4. Clinician reassesses patient recall and comprehension.

5. Patient recalls and comprehends, leading to adherence with treatment recommendation(s).

\section{Consider "Watchful Waiting"}

Watchful waiting is an approach whereby a prescription for an antibiotic is made available with instructions to not immediately administer the antibiotic [34]. Self-care instructions are provided with prescriptions to call their healthcare professional should their symptoms remain or worsen after a specified time period
[35]. The Watchful Waiting Prescription Pad provides recommendations for patients regarding symptom management, monitoring of symptoms, and instructions on what to do if they do not feel better or experience new symptoms (Table 3). A recent study indicates that parental compliance with watchful waiting for their children was predicted by physician explanation and instruction [34]. However, few parents indicated that they received explanations about the antibiotic risk and potential adverse effect(s). This underscores the importance of communication, specifically explanation and discussion of appropriate antibiotic use in addition to risks vs. benefits as tools for deterring unnecessary use. As prescribing is increasingly occurring online, the ability to provide adequate explanation and instruction using this prescription method is unknown but may be compromised. 
Table 3 Health literacy tools for healthcare practitioners

\begin{tabular}{|c|c|c|}
\hline Tool & Utility & References \\
\hline \multicolumn{3}{|l|}{ General } \\
\hline $\begin{array}{l}\text { Health Literacy } \\
\text { Universal Precautions } \\
\text { Toolkit }\end{array}$ & $\begin{array}{l}\text { How to improve both spoken and written } \\
\text { communication, self management, } \\
\text { empowerment }\end{array}$ & Brega et al. [30] \\
\hline $\begin{array}{l}\text { CDC Clear } \\
\text { Communication }\end{array}$ & $\begin{array}{l}\text { Develop and assess public communication } \\
\text { materials }\end{array}$ & $\begin{array}{l}\text { https://www.cdc.gov/ccindex/pdf/full-index- } \\
\text { score-sheet.pdf [13] }\end{array}$ \\
\hline Index (CCI) & Provides plain language resources & $\begin{array}{l}\text { https://www.cdc.gov/healthliteracy/ } \\
\text { developmaterials/plainlanguage.html [36] }\end{array}$ \\
\hline Choosing Wisely & $\begin{array}{l}\text { Promotes conversations between clinicians and } \\
\text { patients with the goal of avoiding unnecessary } \\
\text { treatment }\end{array}$ & http://www.choosingwisely.org/ [32] \\
\hline \multicolumn{3}{|c|}{ Specific to antibiotic use and/or $A M R$} \\
\hline $\begin{array}{l}\text { CDC overview of } \\
\text { community materials }\end{array}$ & $\begin{array}{l}\text { Print materials, videos and audio, social media } \\
\text { messages, and infographics that focus on } \\
\text { appropriate antibiotic use/prescribing and } \\
\text { AMR }\end{array}$ & $\begin{array}{l}\text { https://www.cdc.gov/antibiotic-use/ } \\
\text { community/materials-references/index. } \\
\text { html [37] }\end{array}$ \\
\hline $\begin{array}{l}\text { CDC print materials } \\
\text { for doctors' offices }\end{array}$ & $\begin{array}{l}\text { Posters, brochures, infographics, and fact sheets } \\
\text { available in Chinese, French, Korean, } \\
\text { Portuguese, Spanish, and Vietnamese }\end{array}$ & $\begin{array}{l}\text { https://www.cdc.gov/antibiotic-use/ } \\
\text { community/materials-references/print- } \\
\text { materials/index.html [38] }\end{array}$ \\
\hline $\begin{array}{l}\text { CDC video for } \\
\text { doctors' offices }\end{array}$ & "Antibiotics Aren't Always the Answer" & $\begin{array}{l}\text { https://www.youtube.com/watch?v= } \\
\text { XM0EYKfUxkc [39] }\end{array}$ \\
\hline $\begin{array}{l}\text { CDC watchful } \\
\text { waiting prescription } \\
\text { pads }\end{array}$ & $\begin{array}{l}\text { Administration of a prescription is delayed until } \\
\text { necessary. Provides instruction on symptom } \\
\text { management, when to call the clinician }\end{array}$ & $\begin{array}{l}\text { https://www.cdc.gov/antibiotic-use/ } \\
\text { community/pdfs/aaw/Watchful-Waiting- } \\
\text { Prescription-Pads_small-P.pdf [35] }\end{array}$ \\
\hline $\begin{array}{l}\text { Choosing Wisely } \\
\text { print material }\end{array}$ & $\begin{array}{l}\text { Educate patients about appropriate antibiotic } \\
\text { use. Available in English and Spanish }\end{array}$ & $\begin{array}{l}\text { http://www.choosingwisely.org/wp-content/ } \\
\text { uploads/2018/03/Will-Antibiotics-Help- } \\
\text { Adults_TriFold-Eng.pdf [40] }\end{array}$ \\
\hline \multirow[t]{2}{*}{$\begin{array}{l}\text { American Hospital } \\
\text { Association Physician } \\
\text { Alliance Tools }\end{array}$} & $\begin{array}{l}\text { Clinician resources for outpatient settings, } \\
\text { including webinars and webcasts for clinician } \\
\text { education }\end{array}$ & $\begin{array}{l}\text { http://www.ahaphysicianforum.org/ } \\
\text { resources/appropriate-use/antimicrobial/ } \\
\text { [41] }\end{array}$ \\
\hline & $\begin{array}{l}\text { Patient resources, e.g., infographic on "The ABCs } \\
\text { of Antibiotics" }\end{array}$ & $\begin{array}{l}\text { http://www.ahaphysicianforum.org/ } \\
\text { resources/appropriate-use/antimicrobial/ } \\
\text { content\%20files\%20pdf/APIC- } \\
\text { ABCsAntibiotic.pdf [42] }\end{array}$ \\
\hline
\end{tabular}

$A M R$ antimicrobial resistance, $C D C$ Centers for Disease Control and Prevention 


\section{Identify Opportunities for Shared Decision- Making}

Shared decision-making can be a framework to decrease antibiotic prescribing and help to control AMR if there is a sound basis for antibiotic prescribing. Shared decision-making is the process whereby the clinician and the patient jointly make health decisions after discussing options, benefits, risks, and consideration of patients' values, preferences, and circumstances. Again, few parents recalled discussing risk/benefit as well as the option of delaying antibiotic prescribing for their children (aged 1-12 years) with their clinician [43]. Indeed, most wanted to be involved in the decision. However, training in shared decisionmaking is intensive and may not be appropriate when the healthcare practitioner (HCP) and/or the patient is lacking a basic understanding of AMS health literacy. In addition, shared decision-making in antibiotic prescribing only applies when there is room to consider patient preference [44].

\section{Tracking/Reporting}

Improvement requires assessment. Evaluation of the impact of new approaches to health literacy and AMS is important. Is AMS health literacy improved? Are fewer antibiotics being prescribed? Are patients adhering to their medication as prescribed? Are patients and providers satisfied? These questions can be addressed by gathering data to monitor performance indicator metrics. Patient education materials should be routinely reviewed against the CCI and adherence to AMS health literacy principles tracked and reported. Periodic point prevalence studies could be used to assess AMS health literacy amongst providers and patients and to assess appropriateness of antibiotic prescription rates [45]. Obtaining provider and patient satisfaction scores is also important.

\section{Education/Expertise}

Patient communication should be guided by principles of health literacy. Many tools and resources are available to enhance AMS health literacy as shown in Table 3. Some pertain to health literacy in general such as the Health Literacy Universal Precautions Toolkit. Clear communication strategies can help patients better understand the benefits and risks of antibiotics in addition to making them feel more involved. Recommendations are to greet patients warmly, make eye contact, listen carefully, use plain, nonmedical language, use the patient's words, slow down, limit and repeat content, be specific, and use graphics to illustrate a point.

Patient decision aids are evidence-based educational tools designed to help patients participate in the decision-making process regarding healthcare options [46]. When using decision aids, patients improve their knowledge of the options, feel clearer about what matters to them, have realistic expectations of risk/ benefit, and participate in the decision-making process [47].

Decision aids include pamphlets, videos, or web-based tools [46]. The CDC provides print materials for outpatient healthcare professionals specific to communicating with patients about AMR (Table 3). Compared to usual care, use of a decision aid during the consultation, along with physicians trained in shared decision-making, has been shown to decrease antibiotic prescriptions for upper respiratory infections without negatively impacting clinical outcomes [48].

Because of the complexities and challenges in communicating AMS to individuals with low literacy in particular, all members of the healthcare team should be encouraged to work at the "top of their job descriptions," and specifically engage supportive staff to reinforce AMS principles with patients/care partners. This could be achieved through the development of a protocol and specific training and/or competencies for all staff in both health literacy practices and AMS. Such competencies help to ensure the necessary expertise in AMS health literacy at all levels of personnel.

\section{FUTURE STRATEGIES}

The complexity of AMR mandates multi-pronged and multi-sectoral efforts. One possibility is 
to utilize principles of human-centered design [49] by partnering with community members to self-identify and codevelop approaches that would be effective and seen as most valuable to enhance health literacy, advance AMS, and curb AMR. Engaging members of the community has the added benefit of community education and awareness as well as peer education opportunities.

Another possibility is to collaborate with pharmaceutical companies to support AMS and health literacy initiatives. While it may seem counterintuitive at first pass to see pharmaceutical companies involved in AMS and health literacy because of commercial incentives, upon further consideration, companies should benefit from investments in AMS and health literacy. Ultimately, if a patient understands when a medicine is or is not needed, follows the course of therapy decided with the provider, and is fully informed of potential risks and benefits, then medical innovation is fully realized.

Integration of AMS health literacy into medical and allied health professionals' (dental, physician assistants, nurse practitioners, pharmacist, nurse, medical assistants) curriculums would provide a foundation for communicating with patients about AMR/AMS early on in an HCP's career. Health literacy has already been integrated into curriculums for medical students [50]. Significant short-term improvements were observed after training, but a 1-year follow-up showed declines, indicating the need for longitudinal training. Similarly, it was shown that health literacy training for nurses demonstrated improvements in health literacy knowledge [51]. A recommendation was made to include health literacy in both didactic and clinical courses. For medical professionals who have already received their degree, health literacy training could be part of continuing education. It is likely that these efforts will need to be expanded to train individuals specifically in AMS health literacy.

Patient advocacy groups are currently underutilized and can be strong advocates for improving AMS. They can lobby for increased governmental funding for public education and engagement to address AMR [52]. Patient advocacy groups are particularly well suited to engage the public through powerful stories of adverse outcomes and prevention messages delivered in plain language.

Overall, the evidence base supporting the impact of health literacy interventions on AMS is sparse. Testing alternative communication strategies for explaining AMR and encouraging AMS and evaluating the effect of such strategies on prescriber and patient behavior is needed.

Furthermore, although antimicrobial use is a key driver of AMR, no data exist to demonstrate an association between improved health literacy and reduced AMR. Interestingly, the Netherlands has one of the highest rates of health literacy [53] and the lowest rates of antibiotic use and AMR [54], but a direct association between health literacy and AMR has not been explored. Countries like the Netherlands may provide a base case for further evaluation of their AMS and health literacy strategies and the impact of such strategies on AMR.

\section{CONCLUSION}

The threat of inappropriate antibiotic use is real, yet the public's knowledge of AMS and AMR remains limited. Improved communication between providers and patients is imperative to enhance AMS. We suggest Four Core Elements of Enhancing AMS Health Literacy in the Outpatient Setting, which can be easily applied in clinical practice. Numerous health literacy resources are available to assist providers with incorporation of AMS health literacy considerations into their everyday practice. Whether the initiatives described herein will contribute significantly to the reduction of AMR remains to be seen but should be given due consideration as the alarming threat of AMR continues to increase.

\section{ACKNOWLEDGEMENTS}

Funding. The study was supported by Merck Sharp \& Dohme Corp., a subsidiary of Merck \& Co., Inc., Kenilworth, NJ, USA. The Rapid 
Service and Open Access fees were funded by Merck Sharp \& Dohme Corp., a subsidiary of Merck \& Co., Inc., Kenilworth, NJ, USA. All authors had full access to the articles reviewed in this manuscript and take complete responsibility for the integrity and accuracy of this manuscript.

Medical Writing and Editorial Assistance. Medical writing and editorial assistance were provided by Judith Adams, PharmD and Rosemarie Kelly, PhD, of Churchill Communications, Maplewood, New Jersey. This assistance was funded by Merck Sharp \& Dohme Corp., a subsidiary of Merck \& Co., Inc., Kenilworth, NJ, USA.

Authorship. All named authors meet the International Committee of Medical Journal Editors (ICMJE) criteria for authorship for this article, take responsibility for the integrity of the work as a whole, and have given their approval for this version to be published.

Disclosures. Dr. Elizabeth Hermsen is an employee of Merck Sharp \& Dohme Corp., a subsidiary of Merck \& Co., Inc., Kenilworth, NJ, USA and stockholder of Merck \& Co., Inc., Kenilworth, NJ, USA. Ms. Laurie Myers is an employee of Merck Sharp \& Dohme Corp., a subsidiary of Merck \& Co., Inc., Kenilworth, NJ, USA and stockholder of Merck \& Co., Inc., Kenilworth, NJ, USA. Mr. Christian Lillis reports grants to the Peggy Lillis Foundation from Merck Sharp \& Dohme Corp., a subsidiary of Merck \& Co., Inc., Kenilworth, NJ USA, outside the submitted work. Dr. Erina MacGeorge, Dr. May-Lynn Andresen, and Dr. Bernard Rosof have no conflicts to report.

Compliance with Ethics Guidelines. This article is based on previously conducted studies and does not contain any studies with human participants or animals performed by any of the authors.

Open Access. This article is licensed under a Creative Commons Attribution-NonCommercial 4.0 International License, which permits any non-commercial use, sharing, adaptation, distribution and reproduction in any medium or format, as long as you give appropriate credit to the original author(s) and the source, provide a link to the Creative Commons licence, and indicate if changes were made. The images or other third party material in this article are included in the article's Creative Commons licence, unless indicated otherwise in a credit line to the material. If material is not included in the article's Creative Commons licence and your intended use is not permitted by statutory regulation or exceeds the permitted use, you will need to obtain permission directly from the copyright holder. To view a copy of this licence, visit http://creativecommons.org/licenses/by$\mathrm{nc} / 4.0 /$.

\section{REFERENCES}

1. Peggy Lillis Foundation. C. Diff stories: Peggy Lillis. https://peggyfoundation.org/story/peggy-lillis/. Accessed 11 June 2019.

2. US Department of Health and Human Services: Centers for Disease Control. Antibiotic resistance threats in the United States. 2019. https://www.cdc. gov/drugresistance/pdf/threats-report/2019-ar-thre ats-report-508.pdf. Accessed 11 June 2019.

3. O'Neill J. Tackling drug-resistant infections globally: final report and recommendations. London: The Review on Antimicrobial Resistance; 2016.

4. Fleming-Dutra KE, Hersh AL, Shapiro DJ, et al. Prevalence of inappropriate antibiotic prescriptions among US ambulatory care visits, 2010-2011. JAMA. 2016;315(17):1864-73.

5. The Pew Charitable Trusts. What drives inappropriate antibiotic use in outpatient care? 2017. http://www.pewtrusts.org/-/media/assets/2017/06/ arp_what_drives_inappropriate_antibiotic_use_in_ outpatient_care.pdf. Accessed 16 May 2019.

6. World Health Organization. Global action plan on antimicrobial resistance. 2015. http://www.wpro. who.int/entity/drug_resistance/resources/global_ action_plan_eng.pdf. Accessed 16 May 2019.

7. Sanchez GV, Fleming-Dutra KE, Roberts RM, Hicks LA. Core elements of outpatient antibiotic stewardship. MMWR Recomm Rep. 2016;65(6):1-12.

8. The White House. National action plan for combating antibiotic-resistant bacteria. 2015. https:// 
obamawhitehouse.archives.gov/sites/default/files/ docs/national_action_plan_for_combating_antiboticresistant_bacteria.pdf. Accessed 26 June 2019.

9. Ocan M, Obuku EA, Bwanga F, et al. Household antimicrobial self-medication: a systematic review and meta-analysis of the burden, risk factors and outcomes in developing countries. BMC Public Health. 2015;15:742.

10. Gebrekirstos NH, Workneh BD, Gebregiorgis YS, et al. Non-prescribed antimicrobial use and associated factors among customers in drug retail outlet in Central Zone of Tigray, northern Ethiopia: a cross-sectional study. Antimicrob Resist Infect Control. 2017;6:70.

11. Alividza V, Mariano V, Ahmad R, et al. Investigating the impact of poverty on colonization and infection with drug-resistant organisms in humans: a systematic review. Infect Dis Poverty. 2018;7(1):76.

12. Center for Infectious Disease Research and Policy. Poll: US public aware of antibiotic resistance but sketchy on details. 2019. http://www.cidrap.umn. edu/news-perspective/2019/06/poll-us-public-awareantibiotic-resistance-sketchy-details. Accessed 30 July 2019.

13. Centers for Disease Control and Prevention. CDC Clear Communication Index score sheet. https:// www.cdc.gov/ccindex/pdf/full-index-score-sheet. pdf. Accessed 15 May 2019.

14. Md Rezal RS, Hassali MA, Alrasheedy AA, Saleem F, Md Yusof FA, Godman B. Physicians' knowledge, perceptions and behaviour towards antibiotic prescribing: a systematic review of the literature. Exp Rev Anti Infect Ther. 2015;13(5):665-80.

15. Ratzan SC, Parker RM. Introduction. In: Selden Zorn CM, Ratzan SC, Parker RM, editors. National Library of Medicine current bibliographies in medicine: Health literacy, Bethesda, MD: National Institutes of Health, U.S. Department of Health and Human Services; 2000.

16. Pleasant A, Rudd RE, O'Leary C, et al. Considerations for a new definition of health literacy. NAM Perspectives. Discussion Paper, National Academy of Medicine, Washington, DC. 2016.

17. Nutbeam D. Health literacy as a public health goal: a challenge for contemporary health education and communication strategies into the 21st century. Health Promot Int. 2000;15(3):259-67.

18. U.S. Department of Health and Human Services, Office of Disease Prevention and Health Promotion. America's health literacy: why we need accessible health information. https://health.gov/communi cation/literacy/issuebrief/. Accessed 30 July 2019.
19. Castro-Sánchez E, Moore LS, Husson F, Holmes AH. What are the factors driving antimicrobial resistance? Perspectives from a public event in London, England. BMC Infect Dis. 2016;16:465.

20. Wellcome Trust. Exploring the consumer perspective on antimicrobial resistance. 2015. https:// wellcome.ac.uk/sites/default/files/exploring-consu mer-perspective-on-antimicrobial-resistance-jun15. pdf. Accessed 15 May 2019.

21. World Health Organization. Antibiotic resistance: multi-country public awareness survey. 2015. http://apps.who.int/medicinedocs/documents/s22 245en/s22245en.pdf. Accessed 15 May 2019.

22. Dunn-Navarra AM, Stockwell MS, Meyer D, Larson E. Parental health literacy, knowledge and beliefs regarding upper respiratory infections (URI) in an urban Latino immigrant population. J Urban Health. 2012;89(5):848-60.

23. Salm F, Ernsting C, Kuhlmey A, Kanzler M, Gastmeier P, Gellert P. Antibiotic use, knowledge and health literacy among the general population in Berlin, Germany and its surrounding rural areas. PLoS One. 2018;13(2):e0193336.

24. Castro-Sánchez E, Chang PWS, Vila-Candel R, Escobedo AA, Holmes AH. Health literacy and infectious diseases: why does it matter? Int J Infect Dis. 2016;43:103-10.

25. Micallef C, Kildono K, Castro-Sánchez E, et al. Patient and public understanding and knowledge of antimicrobial resistance and stewardship in a UK hospital: should public campaigns change focus? J Antimicrob Chemother. 2017;72:311-4.

26. Gualano MR, Gili R, Scaioli G, Bert F, Siliquini R. General population's knowledge and attitudes about antibiotics: a systematic review and metaanalysis. Pharmacoepidemiol Drug Saf. 2015;24(1): 2-10.

27. McCullough AR, Parekh S, Rathbone J, Del Mar CB, Hoffmann TC. A systematic review of the public's knowledge and beliefs about antibiotic resistance. J Antimicrob Chemother. 2016;71(1):27-33.

28. Brach C, Keller D, Hernandez LM, et al. Ten attributes of health literate health care organizations. 2012; Institute of Medicine. https://nam.edu/wpcontent/uploads/2015/06/BPH_Ten_HLit_Attributes. pdf. Accessed 15 May 2019.

29. Koh HK, Berwick DM, Clancy CM, et al. New federal policy initiatives to boost health literacy can help the nation move beyond the cycle of costly 'crisis care'. Health Aff (Millwood). 2012;31(2):434-43. 
30. Brega AG, Barnard J, Mabachi NM, et al. AHRQ Health Literacy Universal Precautions Toolkit, Second Edition. 2015 Colorado Health Outcomes Program, University of Colorado Anschutz Medical Campus under Contract No. HHSA290200710008, TO\#10. AHRQ Publication No. 15-0023-EF. Rockville, MD.

31. Centers for Disease Control and Prevention. The CDC Clear Communication Index: Index Widget. https://www.cdc.gov/ccindex/index.html?CDC_AA _refVal=https $\% 3 \mathrm{~A} \% 2 \mathrm{~F} \% 2 \mathrm{Fwww} . c d c . g o v \% 2 \mathrm{Fhealth}$ communication $\% 2$ Fclearcommunicationindex $\%$ 2Findex.html. Accessed 26 June 2019.

32. ABIM Foundation. Choosing Wisely: promoting conversations between patients and clinicians. http:// www.choosingwisely.org. Accessed 30 July 2019.

33. Schillinger D, Piette J, Grumbach K, et al. Closing the loop: physician communication with diabetic patients who have low health literacy. Arch Intern Med. 2003;163(1):83-90.

34. MacGeorge EL, Caldes EP, Smith RA, Hackman NM, San Jose A. Reducing unwarranted antibiotic use for pediatric acute otitis media: the influence of physicians' explanation and instruction on parent compliance with 'watchful waiting'. J Appl Commun Res. 2017;45(3):333-45.

35. Centers for Disease Control and Prevention. What is watchful waiting? https://www.cdc.gov/anti biotic-use/community/pdfs/aaw/Watchful-WaitingPrescription-Pads_small-P.pdf. Accessed 26 June 2019.

36. Centers for Disease Control and Prevention. Health literacy: plain language materials \& resources. 2016. https://www.cdc.gov/healthliteracy/developmateri als/plainlanguage.html. Accessed 26 June 2019.

37. Centers for Disease Control and Prevention. Antibiotic prescribing and use in doctor's offices: materials and references. https://www.cdc.gov/ antibiotic-use/community/materials-references/ index.html. Accessed 26 June 2019.

38. Centers for Disease Control and Prevention. Antibiotic prescribing and use in doctor's offices: patient and physician information. https://www. cdc.gov/antibiotic-use/community/materials-refer ences/print-materials/index.html. Accessed 26 June 2019.

39. Centers for Disease Control. Antibiotics aren't always the answer. https://www.youtube.com/ watch?v=XMOEYKfUxkc. Accessed 26 June 2019.

40. American Academy of Pediatrics. Antibiotics: will they help you or hurt you? http://www. choosingwisely.org/wp-content/uploads/2018/03/
Will-Antibiotics-Help-Adults_TriFold-Eng.pdf. Accessed 17 May 2019.

41. AHA Physician Alliance. Antimicrobial stewardship. http://www.ahaphysicianforum.org/resources/app ropriate-use/antimicrobial/. Accessed 17 May 2019.

42. Association for Professionals in Infection Control and Epidemiology. The ABC's of antibiotics. http:// www.ahaphysicianforum.org/resources/appropriate -use/antimicrobial/content\%20files\%20pdf/APICABCsAntibiotic.pdf. Accessed 17 May 2019.

43. Coxeter PD, Mar CD, Hoffmann TC. Parents' expectations and experiences of antibiotics for acute respiratory infections in primary care. Ann Fam Med. 2017;15(2):149-54.

44. Brabers AE, Van Esch TE, Groenewegen PP, et al. Is there a conflict between general practitioners applying guidelines for antibiotic prescribing and including their patients' preferences? Patient Prefer Adherence. 2018;12:9-19.

45. Cotta MO, Robertson MS, Upjohn LM, Marshall C, Liew D, Buising KL. Using periodic point-prevalence surveys to assess appropriateness of antimicrobial prescribing in Australian private hospitals. Int Med J. 2013;44(3):240-6.

46. Stacey D, Légaré F, Lewis K, et al. Decision aids for people facing health treatment or screening decisions. Cochrane Database Syst Rev. 2017;4: CD001431.

47. Australian Commission on Safety and Quality in Health Care. Shared decision making: decision support tools for patients. https://www. safetyandquality.gov.au/our-work/shared-decisionmaking/patient-decision-aids/. Accessed 11 June 2019.

48. Légaré F, Labrecque M, Cauchon M, Castel J, Turcotte S, Grimshaw J. Training family physicians in shared decision-making to reduce the overuse of antibiotics in acute respiratory infections: a cluster randomized trial. CMAJ. 2012;184(13):E726-34.

49. Chen E, Leos C, Kowitt SD, Moracco KE. Enhancing community-based participatory research through human-centered design strategies. Health Promot Pract. 2020;21(1):37-48.

50. Coleman CA, Peterson-Perry S, Bumsted T. Longterm effects of a health literacy curriculum for medical students. Fam Med. 2016;48(1):49-53.

51. McCleary-Jones V. A systematic review of the literature on health literacy in nursing education. Nurse Educ. 2016;41(2):93-7. 
52. Nichols K, Stoffella S, Meyers R, Girotto J, Advocacy Committee for the Pediatric Pharmacy Advocacy Group. JPPT position statement: pediatric antimicrobial stewardship programs. J Pediatr Pharmacol Ther. 2017;22(1):77-80.

53. Sørensen K, Pelikan JM, Rothlin F, et al. Health literacy in Europe: comparative results of the European health literacy survey (HLS-EU). Eur J Pub Health. 2019;25(6):1053-8.
54. McDonnell L, Armstrong D, Ashworth M, Dregan A, Malik U, White P. National disparities in the relationship between antimicrobial resistance and antimicrobial consumption in Europe: an observational study in 29 countries. J Antimicro Chemother. 2017;72:3199-205. 